\title{
Metallography, Microstructure, and Analysis Updates Aims and Scope
}

(c) Springer Science+Business Media New York and ASM International 2016

With this first issue of 2016, Metallography, Microstructure, and Analysis enters its fifth year of publication. This is an appropriate time to examine the Aims and Scope for the journal and identify areas that require clarification. Additionally, considering the multitude of scholarly publications currently available to authors, it is important that MMA clearly identifies those topics that are especially of interest to the journal.

The topics of the submissions that have been received by the journal over the past 4 years have provided insight into our readers' interpretation of the journal's focus areas. Some items in the Aims and Scope as written when the journal launched were likely not clear to our authors. The Aims and Scope have recently been updated to provide clarification on which topics the journal will and will not cover. It is the hope of the editorial staff that the updated Aims and Scope will more clearly define the topics that will be considered for publication in Metallography, Microstructure, and Analysis.

Ryan Deacon Editor-in-Chief

\section{Aims and Scope}

The official journal of the International Metallographic Society, Metallography, Microstructure, and Analysis publishes original, peer-reviewed research articles on engineered materials, which are defined as being both processed and inorganic. The journal focuses on the science and practice of preparing, interpreting, and analyzing microstructures for the purpose of understanding material behavior and performance. Metallography, Microstructure, and Analysis serves as a forum for engineers and scientists to exchange the latest information regarding the evolution of microstructures in a variety of materials.

The journal covers novel and alternative methods for microstructural examination and interpretation (including metallography, microscopy, and diffraction), and techniques for physical and chemical analysis as they relate to microstructure. The scope includes microstructure modeling and computer-aided microstructure analysis techniques.

Papers that discuss the theoretical and experimental development of a microstructure and the impact of the microstructure on materials properties are considered particularly appropriate for the journal. Specifically, the journal publishes contributions that discuss the ways in which microstructures can influence, or arise from:

1. Mechanical and thermal processing

2. Environmental degradation (such as oxidation and corrosion)

3. Welding, casting, and solidification processes

4. Additive or digital manufacturing techniques, and

5. Failure of engineering structures.

In addition to these general topics, the journal covers a wide range of more specialized materials science and metallurgy issues, such as the characterization of building materials, archeometallurgy, high-strain-rate phenomena, tribological surfaces, and interfaces.

Contributions that present a complete treatment of a microstructure, from its formation to preparation techniques to interpretation and analysis, are especially of interest to the journal.

The journal does not publish papers on organic materials, or papers that do not contain discussion of the microstructure of an engineering material. 